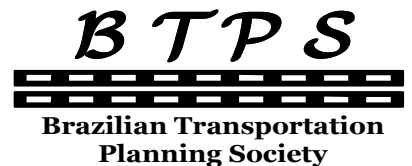

Planning Society
Journal of Transport Literature

Vol. 8, n. 3, pp. 62-88, Jul. 2014

Research Directory
JTL | RELIT www.transport-literature.org
ISSN 2238-1031

\title{
Indicadores do desenho urbano e sua relação com a propensão a caminhada
}

[Indicators for urban design and their relationship with the propensity to walk]

\author{
André Ricardo Prazeres Rodrigues*, Josefina Flórez, \\ Denise Beer Frenkel, Licinio da Silva Portugal
}

Federal University of Rio de Janeiro - Brazil, Simón Bolívar University - Venezuela, Federal University of Rio de Janeiro - Brazil, Federal University of Rio de Janeiro - Brazil

Submitted 6 May 2013; received in revised form 30 Sep 2013; accepted 1 Nov 2013

\begin{abstract}
Resumo
A viagem a pé envolve certas condições frequentemente denominadas como caminhabilidade, observando-se vários estudos que buscam estabelecer, não só os fatores que interferem nela como os indicadores usados para medi-la. Um destaque vem sendo dado ao ambiente construído e, em particular, ao desenho urbano, que configura a rede de caminhos. A configuração desta rede, sua densidade e conectividade afetam os tempos, a continuidade dos deslocamentos a pé, bem como o número de itinerários alternativos. A partir da revisão da bibliografia e dos índices disponíveis na Teoria dos Grafos, estabelecem-se os indicadores mais adequados para representar o desenho urbano e para investigar a influência da configuração da rede de caminhos na propensão a caminhada. Conceitualmente, indicadores derivados dos ciclos tendem a melhor explicar a conectividade. Sugere-se ainda, de forma exploratória, uma escala, baseada em indicadores de fácil obtenção, que expresse o potencial de uma dada área favorecer as viagens a pé, de acordo com tal configuração. Essa escala pode contribuir para a escolha de áreas para a implantação de Polos Geradores de Viagens orientados aos pedestres.
\end{abstract}

Palavras-Chave: viagens a pé, rede de caminhos, desenho urbano, caminhabilidade, teoria dos grafos.

\begin{abstract}
The propensity of people to travel on foot involves diverse conditions, often categorized by the term walkability. Various studies have been conducted to establish both the factors that influence walkability and the indicators used to measure it. Particular interest has been focused on the built environment, specifically the urban design, represented by the road network. The configuration of this network, its density and connectivity affect the times and continuity of travel on foot as well as the number of alternative routes. Based on a review of the literature and the indexes available in graph theory, we establish the most suitable indicators to represent to urban design, which can be used to investigate the influence of the configuration of the network on people's propensity to travel on foot. Conceptually, indicators based on cycles tend to explain connectivity better. From this review and in exploratory form, we suggest a scale based on easily obtained indicators that express the potential of a given area to favor walking, according to its configuration. This scale can contribute to choice the most suitable areas for establishing trip generation hubs oriented to pedestrians.
\end{abstract}

Key words: travel on foot, road network, urban design, walkability, graph theory.

*Email: andre_rodrigues@pet.coppe.ufrj.br.

\section{Recommended Citation}

Rodrigues, A. R. P., Flórez, J. , Frenkel, D. B. and Portugal, L. S. (2014) Indicadores do desenho urbano e sua relação com a propensão a caminhada. Journal of Transport Literature, vol. 8, n. 3, pp. 62-88.

- JTL/RELIT is a fully electronic, peer-reviewed, open access, international journal focused on emerging transport markets and published by BPTS - Brazilian Transport Planning Society. Website www.transport-literature.org. ISSN 2238-1031. 


\section{Introdução}

Diferentemente das políticas de transportes e de uso do solo adotadas pelo menos nas últimas quatro décadas, que se caracterizaram por procurar atender predominantemente as necessidades das viagens por automóveis (NZTA, 2013), crescem os movimentos direcionados às cidades sustentáveis, que vêm exigindo uma mudança de paradigma e de foco (Rocha et al., 2012). Nesse contexto, tem-se valorizado uma abordagem mais abrangente, interdisciplinar e multimodal (Litman, 2013a), priorizando as modalidades menos agressivas ambientalmente, como o transporte público e o não motorizado, em particular os deslocamentos a pé, que se caracterizam pelos seus evidentes efeitos positivos em termos de redução da poluição, conservação de recursos naturais, suporte à economia local, incremento do sentimento de segurança e melhora da saúde pública (Litman, 2009; Jonietz e Timpf, 2012).

Essa preocupação se torna ainda mais premente em condições de uso do solo concentrado no espaço, como é o caso dos denominados Polos Geradores de Viagens - PGVs, que, ao atraírem grandes contingentes de viagens, tendem a produzir impactos mais expressivos no sistema viário de acordo com a parcela dos usuários que se deslocam por automóveis (Portugal, 2012).

Assim, e levando em conta o papel da caminhada nesse processo direcionado às modalidades mais produtivas socialmente, não há dúvida de que é fundamental se investir na infraestrutura destinada aos pedestres. Isso é o básico. Mas é preciso, além disto, avançar na construção de um ambiente que incentive que mais viagens sejam feitas a pé, o que requer se estudar os fatores que interferem nessa escolha modal e as estratégias que podem contribuir para o seu sucesso e para uma mobilidade sustentável.

Considera-se que a realização da viagem a pé envolve certas condições frequentemente denominadas pelo termo genérico de "caminhabilidade" que, segundo Park (2008), significa a qualidade do ambiente percebido pelos pedestres. Características relacionadas à caminhabilidade compreendem escalas mais abrangentes que podem cobrir uma área, um 
bairro ou mesmo se estender a toda a cidade, como também podem se direcionar a micro escala em termos de itinerários e segmentos de via (Alfonso et al., 2008).

Vários estudos vêm sendo conduzidos com vistas a estabelecer, por um lado, os indicadores que refletem a caminhabilidade e podem ser usados para medi-la (Kelly et al., 2011; Maghelal e Capp, 2011; Hirsch et al., 2013; Wey e Chiu, 2013). Por outro lado, determinar os fatores que expressam as condições que tornam uma área caminhável, favorecendo o andar a pé, bem como investigar a sua correlação com uma divisão modal orientada ao pedestre (Saelens et al., 2003). Em ambos os casos, um destaque vem sendo dado ao ambiente construído (Ewing e Cervero, 2010).

Dentre as várias dimensões que caracterizam o ambiente construído, uma delas vem assumindo um papel de relevo: o desenho urbano, conforme registrado por várias pesquisas relativamente recentes, como citado por Gallagher et al. (2010) e Jonietz e Timpf (2012). O Desenho Urbano compõe a rede de caminhos e, em função da sua configuração, determina não só o comprimento como a quantidade de itinerários entre dois nós potenciais geradores de viagens influenciando a facilidade de caminhada e, consequentemente, a geração de viagens a pé (Hillier et al., 1993; Rodrigues, 2013). Litman (2013b) ainda considera que tal rede, dependendo de sua densidade e conectividade, também afeta os tempos e a continuidade dos percursos, bem como a acessibilidade e distribuição mais equitativa dos fluxos de pedestres e também de veículos.

Nesse sentido pretende-se, inicialmente, estabelecer - a partir da revisão da bibliografia existente e dos índices disponíveis na Teoria dos Grafos - os indicadores mais adequados para representar o desenho urbano e que possam ser usados para investigar a influência da configuração da rede de caminhos na propensão das viagens serem realizadas a pé. Por outro lado, a partir dessa revisão e de forma exploratória, pretende-se sugerir uma escala, baseada em indicadores simples e de fácil obtenção, que expresse a propensão de uma dada área favorecer as viagens a pé, de acordo com tal configuração. Essa escala pode ser empregada de maneira expedita e estratégica na escolha de localidades potencialmente atraentes para as viagens a pé e que poderiam ser candidatas para a implantação de determinados PGVs. Espera-se, assim, desestimular o uso do automóvel e orientar a demanda de viagens para o deslocamento não motorizado, proporcionando a viabilidade do empreendimento sem perder de vista o compromisso com a qualidade de vida dos moradores. 


\section{Caracterização das viagens a pé e aspectos intervenientes}

O andar a pé é uma condição natural do ser humano (Daros, 2000; Rocha et al., 2012; Rodríguez, 2013) e o principal meio de deslocamento nas áreas urbanas até que as novas tecnologias de transporte desenvolvidas nos finais dos séculos XIX e início do XX permitiram mobilizar altos volumes de pessoas por unidade de tempo, principalmente por meio de modalidades coletivas e públicas sobre rodas (Rodrigue et al., 2009). Depois da Segunda Guerra Mundial, a popularização do uso do automóvel, junto com o desenvolvimento de uma rede viária de maior capacidade e a aplicação da regulamentação de zoneamento para produzir uso do solo uniforme, incentivaram a expansão da cidade, resultando em um modelo de ocupação urbana disperso e segregado por tipo de atividade, assim como bairros com redes pouco conectadas (Hall,1993; Flórez, 1998; Rodrigue, 2013). Neste contexto se deram as condições para a implantação de grandes empreendimentos, ou PGVs, como os shopping centers e parques metropolitanos, muitas vezes afastados dos centros urbanos e acessíveis somente por meio de veículo particular. Ainda que este tipo de desenvolvimento ocorreu predominantemente nas cidades dos Estados Unidos, também há prevalecido em outros países, como os latinoamericanos, nos quais se observa normalmente uma acentuada segregação social do espaço (Sabatini, et al., 2001; ONU-Habitat, 2012). Neste modelo de ocupação urbana, o pedestre foi deixado de lado e o projeto viário priorizou a fluidez e a velocidade. Particularmente na América Latina se privilegiaram os modos motorizados em detrimento dos pedestres e ciclistas, apesar destes serem mais numerosos e vulneráveis, conforme estabelece a segurança viária (Portugal et al., 2010; ONU-Habitat, 2012).

Alguns autores advertem sobre as consequências ambientais e sociais desse modelo. Buchanan (1964), em seu conhecido relatório, Traffic in Towns, alerta sobre o consumo intensivo do automóvel e os problemas que poderiam acarretar do congestionamento, como poluição e acidentes de trânsito, chamando também a atenção sobre a necessidade de um planejamento mais integrado do uso do solo e do transporte que favoreça as modalidades não motorizados e o transporte público. Em 1961, Jane Jacobs faz seu famoso ataque contra a habitação moderna e o planejamento da época, além de questionar a nociva segregação, defendendo a manutenção da diversidade e da vida nas ruas, próprias do antigo modelo de cidade (Appleyard, 1981). Da mesma maneira, Appleyard (1981) analisa como a intensidade e a composição do tráfego afeta negativamente a população residente. 
Desde finais da década de 1980 observa-se na agenda urbana o surgimento de novas tendencias e movimentos que têm em comum a busca da sustentabilidade por meio de um planejamento que responda de forma integral à realidade política, social, econômica e ecológica das cidades (Wheeler, 2004). Em particular, muitos desses movimentos defendem as modalidades de transporte mais sustentáveis, desenhos urbanos e projetos viários que facilitem as viagens a pé ou que promovam ambientes mais "caminháveis", a mescla de usos de solo e a diversidade urbana. Alguns deles são: Novo Urbanismo, New Traditional Neighborhood Design, Smart Growth, Transit Oriented Development e Livable Communities (Portugal, 2012).

Por outro lado, nos últimos anos, os resultados de pesquisas ressaltam os beneficios da caminhada na saúde, em especial na prevenção de enfermidades crônicas e da obesidade (Bradshaw, 1993; FHWA, 2012; Rocha et al., 2012; Rodrigues, 2013; VTPI, 2013) e sugerem relações entre o ambiente construído e a promoção dessa modalidade de transporte (Frank e Engelke, 2001; Vojnovic et al., 2006; Litman, 2008; Marko e Johnson, 2008; FHWA, 2012).

Além dos benefícios na saúde e na qualidade de vida, a caminhada não é poluente, permite o acesso às atividades locais e é acessível a todas as pessoas sem distinção social ou demográfica (FHWA, 2012; Rocha et al., 2012). Por outro lado, a presença de pedestres no espaço público influencia na sensação de segurança e proporciona condições que favorecem as interações pessoais e a coesão social (Appelyard, 1981; FHWA, 2012; VTPI, 2013). A movimentação de pedestres interfere na economia local por meio das interações entre as atividades e serviços. O custo dessa interação depende da distância entre a origem e o destino (Robusté, 2010; Rodrigues, 2013). Outro aspecto a destacar é que o valor dos investimentos em infraestrutura para os pedestres é significativamente inferior ao requerido pelos modos motorizados, além de ser a opção mais econômica para o usuário (FHWA, 2012). Neste sentido, na América Latina observa-se que as viagens a pé são realizadas em maior proporção pelos segmentos de menor poder aquisitivo e pelas mulheres, muitas vezes em condições muito precárias (Cervero et al., 2009; CAF, 2010; Portugal et al. 2010; AMB, 2012).

Os deslocamentos a pé se realizam no início e no final de todas as modalidades de transporte, assim como na conexão entre elas (NZTA, 2009; Austroads, 2013; VTPI, 2013). Adicionalmente, as viagens a pé representam uma parcela importante do total de viagens feitas, para o caso das cidades da Austrália, entre 10 e 20\% (VTPI, 2013). No caso da 
América Latina essa proporção é ainda mais significativa. De acordo com dados de quinze cidades dessa região, mais de $28 \%$ das viagens se realizam a pé e de bicicleta (CAF, 2010). Vale destacar que a pesquisa sobre mobilidade realizada em 2010 em Bogotá registra que 46\% das viagens com mais de 3 minutos de duração ocorrem a pé, e para as viagens superiores a 15 minutos, este modo representa 28\% (AMB, 2011). Apesar de sua importância, o planejamento de transportes tradicionalmente considera o deslocamento a pé como um meio complementar ou de segunda categoria, desprezando seu papel como modo de transporte (NZTA, 2009). Tal tratamento contribuiu para restringir, por um lado, a caminhada como uma alternativa de transporte para distâncias longas e, por outro, na forma como se realizam pesquisas de mobilidade, muitas vezes considerando apenas as viagens com mais de 10 ou 15 minutos, algumas pessoas entrevistadas tendem a não declarar as viagens a pé por considerálas irrelevantes (VTPI, 2013).

De acordo com a perspectiva do indivíduo, os principais fatores que afetam a decisão de realizar viagens a pé, diante da opção de outras modalidades de transporte, são classificados por alguns autores como: características pessoais (culturais, socioeconômicas, disponibilidade de automóvel, condições físicas, aspectos psicológicos); características da viagem (distância e tempo, propósito e se carrega algum volume) e fatores ambientais (construído, social e natural) (FHWA, 1999; Moudon, et al., 2002; Flórez, 2007; Rocha et al., 2012). Alguns autores enfatizam a qualidade da infraestrutura destinada ao pedestre (Khisty, 1994; Araújo et al., 2000; TRB, 2000) e outros consideram a oferta de transporte como um aspecto a parte (Amãncio e Sanches, 2005; Schneider et al., 2009), diferentemente de alguns estudos que os incluem como parte do ambiente construído, como será tratado neste artigo. Estas variáveis influenciam e são influenciadas entre si, sendo que o peso atribuído a tais variáveis e interações dependerá do modelo de decisão adotado pelo individuo (Flórez, 2007; Scovino, 2008; Rocha et al., 2012).

Assumindo que as condições do ambiente construído influenciam nas decisões de realizar viagens a pé, distintas investigações buscaram estabelecer quais são aquelas que definem uma área, rua ou um trajeto como "caminhável" (walkable), assim como indicadores de caminhabilidade (walkability), a fim de medir esta condição. Segundo Speck (2012), a caminhabilidade é, ao mesmo tempo um fim e um meio, assim como uma medida. A caminhabilidade contribui com a vitalidade urbana mas também é um indicador dessa 
vitalidade. A fim de lograr localidades urbanas mais exitosas e habitáveis, de acordo com o autor, o aspecto que mais influi é a condição de caminhabilidade e esta personifica esse êxito. Indica que o tecido urbano, referindo-se à forma como o conjunto das ruas, quarteirões e edifícios que se articulam em torno de monumentos emblemáticos, algumas vezes caracterizados como Polos Geradores de Viagens, é um dos aspectos chaves para favorecer a caminhabilidade. Nessa direção, Gehl e Gemzoe (2003) e Kelly et al. (2011) enfatizam que a caminhabilidade pode ser entendida tanto como um indicador como um meio para melhorar o espaço público. Caminhabilidade indica, portanto, em que medida o ambiente construído é considerado como adequado ou aceitável para caminhar, em termos de atributos físicos e percebidos; portanto, reflete a qualidade das condições que compreendem a caminhada (Austroads, 2013).

Existe um grande interesse dos pesquisadores em estabelecer as relações causais entre o ambiente construído e transporte (Hess et al., 2001). O ambiente construído pode ser analisado pelo desenho urbano e uso do solo (Crane, 1999). As variáveis do uso do solo mais usadas para explicar as viagens são densidade e diversidade (Hess et al., 2001). Moudon et al. (2006) citam que as variáveis do ambiente construído que mais explicam as condições de caminhabilidade são: maior densidade, proximidade de distintas atividades e quarteirões pequenos. Nesse contexto, autores como Cervero e Kockelman (1997), Cervero e Duncan (2003) e Krizek (2003) contemplaram três principais dimensões influenciando a realização de viagens: densidade, diversidade e desenho urbano. Outras duas dimensões foram incluídas posteriormente: o destino acessível e a disponibilidade de transporte público (Cervero et al., 2009; Ewing e Cervero, 2010).

Conforme Rocha et al. (2012), a densidade é a intensidade do uso do solo em termos de habitação, emprego e outras atividades em determinada área; a diversidade reflete a heterogeneidade do uso do solo e interfere na proximidade das atividades; o desenho urbano refere-se à qualidade e à configuração física da malha viária, influenciando na continuidade e na conectividade da rede de caminhos dos pedestres; destino acessível compreende o tipo e quantidade de atividades e oportunidades disponíveis em seu entorno e a disponibilidade de transporte público é obtida pela acessibilidade ao mesmo. Dentre essas dimensões, um destaque será dado para o desenho urbano, dimensão na qual se caracterizam as viagens a pé através da rede de caminhos, constituída por um conjunto de nós e ligações e é nesta visão de 
conjunto que se buscará compreender como a configuração dessa rede pode influenciar os deslocamentos a pé (Rodrígues, 2013).

\section{Desenho urbano e sua influência na geração de viagens a pé}

O desenho urbano lida com a dimensão físico espacial das cidades. Deve articular e conectar as boas práticas da Arquitetura, do Urbanismo e da Engenharia de Transportes na busca da promoção das potencialidades do ambiente construído na conversão de suas limitações em oportunidades, de forma a aproveitar e promover o contato social, a vitalidade comercial e a eficiência da cidade (Villota, 2001; Del Rio, 2004; Cuthbert, 2005). O desenho urbano, ao considerar o pedestre como elemento central, é capaz de afetar diretamente o número das viagens a pé, nas diferentes áreas, de acordo com a estruturação de suas conexões e instalações (VTPT, 2007; Frenkel, 2008).

Uma das características do desenho urbano propício à caminhada é a sua conectividade em toda a rede, suas diversas rotas interligadas, de modo a propiciar o recobrimento de toda a área e possibilitar que todo o deslocamento, da origem ao destino, possa ser feito a pé (NZTA, 2007).

Padrões de uma rede viária mais compacta e interligada, com uso de solo intensificado, refletem na escolha modal e na frequência de viagens (Cervero e Kockelman, 1997), fomentando os deslocamentos a pé.

Pesquisas relacionadas à caminhada podem ficar delegadas a uma segunda importância se comparadas a outros modos, pois o modo a pé exige uma infraestrutura limitada (NZTA, 2007). Entretanto, a busca de ferramentas que sistematizem a qualificação e a quantificação dessa infraestrutura equipara a sua importância aos demais sistemas de transporte (Abley e Tuner, 2011).

Maghelal e Capp (2011) analisaram diversos trabalhos relevantes, produzidos nas últimas duas décadas, com o objetivo de identificar, selecionar, avaliar atributos e variáveis intervenientes à caminhabilidade na dimensão do desenho urbano, de forma a organizar as principais variáveis associadas à caminhabilidade. Uma das dificuldades neste tipo de estudo 
está na natureza das medidas, pois alguns aspectos do ambiente construído para os pedestres podem ser mensurados objetivamente, mas outros são de natureza subjetiva.

Abley e Tuner (2011) estudaram, com base no Guia do NTZA para Avaliação de Ruas (2010), que correlaciona características físicas e operacionais do desenho urbano (medições quantitativas) e combinaram a esta metodologia a percepção de caminhabilidade (medição qualitativa), fornecendo uma série de formulações matemáticas de obtenção de nível de serviço que leve a predição de comprimentos de trajetos e travessias, conforme a qualidade do ambiente construído. Consideram uma ferramenta capaz de identificar áreas de fraco desempenho, porém com potenciais melhorias e novas propostas.

Krizek (2003) propõe, a partir de uma ampla revisão bibliográfica, um índice de medição do nível de acessibilidade aos pedestres de um bairro, considerando os elementos associados às dimensões densidade, diversidade e desenho urbano. Segundo Rodriguez (2013), o estudo verifica que a densidade pode ser captada com certa facilidade; que os elementos sobre a população e emprego não podem estar separados devido a sua forte relação e que juntos refletem a dimensão densidade; e que a diversidade é representada pela sinergia entre as diferentes atividades (comercial, residencial, entre outras) e as proximidades entre si, diminuindo a dependência do automóvel.

O desenho urbano é formado por um conjunto de vias que atendem a diferentes modalidades de transportes e usuários (Rodrigue et al., 2009; Stantec, 2010; ITE, 2011), onde são alocados os diferentes modos de transporte, e se configura em uma rede que pode assumir diferentes formas (Rodrigue et al., 2009; Mitra et al., 2010), como retilíneas e uniformes (rede em malha), retas e curvilíneas com um centro em comum (rede radial ou estrela) ou disformes (geralmente num padrão linear ou árvore). As vias caracterizam uma rede que pode assumir diversos caminhos, formados por nós (interseções e travessias) e ligações (ruas e calçadas) (Blumenfeld-Lieberthal, 2009; Rodrigue et al., 2009; Reggiani et al., 2010). Uma rede de caminhos mais curtos e com mais opções de trajetos beneficia a caminhada (Ewing e Cervero, 2010; TransLink, 2010; Kelly et al., 2011), o que pode ser medido pela quantidade de nós, ligações e ciclos, ou seja, sua topologia (Parthasarathi, 2011; Rocha et al., 2012; Parthasarathi e Levinson, 2013). Segundo Krizek (2003), é preferível medir a influência do desenho urbano nas viagens a pé pelo tamanho dos quarteirões ou pela intensidade de interseções do que por sua forma geométrica. 
Litman (2008) compara as distâncias de abrangência, por modo de transporte: para o pedestre são consideradas 36 quadras, para o ciclista 256 quadras e para o automóvel 2.500 quadras, assim, considerando os 5 minutos de caminhada, um pedestres é capaz e alcançar 3 quadras, enquanto o automóvel, a $40 \mathrm{~km} / \mathrm{h}$ alcançaria 25 quadras. As distâncias máximas de caminhadas não são consensuais e irão variar de acordo as condições geográficas, climáticas, hora do dia, padrão do uso do solo, características do pedestre e motivo da viagem (GDOT, 2003). Rotas mais confortáveis podem encorajar mais viagens a pé, com o vencimento de maiores distâncias (Frenkel, 2008).

Para facilitar a medição da rede de caminhos no seu comprimento e trajetos, Parthasarathi (2011) classifica em quatro categorias a relação entre nós, ligação e ciclo na rede de caminhos, a saber:

- Hierarquia: refere-se à formação dos trajetos, às diferenças entre a rede de caminhos, ou opções de trajetos, que são o número de mudanças de direção do ponto de origem ao destino;

- Topologia: identifica as conectividades e o padrão de conexão da rede de caminhos, que se relaciona à ideia de nós, ligações e a formação de ciclos, que são usados para medir a eficiência da rede;

- Morfologia: descreve a regularidade da rede de caminhos, suas formas (compacta, espraiada, reticulada, entre outros) e divisões, uma relação entre o perímetro e a área de estudo, considerando-se o trajeto percorrido;

- Escala: identifica a intensidade da rede de caminhos dentro de uma área, conforme a densidade de nós e ligações.

Rodrigues (2013) destaca que tanto o "nó" como a "ligação" estão presentes nas quatro categorias.

Logo, a configuração da rede de caminhos poderá interferir nas viagens a pé, mas não se devem desconsiderar as outras dimensões mencionadas anteriormente. 
Como visto, a adoção de projetos com desenho urbano bem estruturado pode resultar na mudança de comportamento, reduzido à dominação do tráfego motorizado e assegurar o acesso de pessoas às suas atividades por meio da caminhada (Frenkel, 2008). Uma infraestrutura adequada oferece conexões apropriadas entre origens e destinos, o que inclui distância para os pontos de ônibus, estações e terminais de transporte público dentro do ambiente construído (Moudon et al., 2002; Cervero et al., 2009). As viagens a pé no desenho urbano, o comprimento e o número dos caminhos devem ser compatíveis com as distâncias de caminhada (Rodrigues, 2013), pois os pedestres possuem limitações físicas que restringem sua área de acesso (Rocha et al., 2012).

Neste contexto, o desenho urbano já existente dificilmente pode ser alterado (Parthasarathi, 2011), compreendê-lo pode ajudar na construção de novas localidades e em adequações de setores existentes da cidade, além de permitir investigar o grau e a qualidade de acesso dos pedestres. Por isto, a necessidade de se estudarem os indicadores que medem a influência do desenho urbano nas viagens a pé.

\section{Indicadores Tradicionais}

A fim de se selecionar e classificar os indicadores que buscam medir a influência da configuração da rede de caminhos na propensão da caminhada, procedeu-se a consulta a dois grupos de referências bibliográficas: um que se preocupou em medir tal interferência e outro que procurou estabelecer o índice de caminhabilidade considerando o papel do desenho urbano no processo.

Alguns autores relacionaram um conjunto de elementos que expressam a influência do desenho urbano na propensão das viagens a pé, conforme mostra a Tabela 1, na qual se destacam os indicadores tradicionais. 
Tabela 1 - Elementos e variáveis do desenho urbano.

\begin{tabular}{|c|c|c|c|c|c|}
\hline \multicolumn{2}{|c|}{ Elementos } & $\begin{array}{c}\text { Cervero e } \\
\text { Kockelman (1997) }\end{array}$ & $\begin{array}{c}\text { Cervero e Duncan } \\
(\mathbf{2 0 0 3})\end{array}$ & Krizek (2003) & $\begin{array}{l}\text { Cervero et al. } \\
\text { (2009) }\end{array}$ \\
\hline \multicolumn{2}{|c|}{ Áreas de estudo } & 321 metros de raio & $\begin{array}{l}1.600 \text { metros de } \\
\text { raio }\end{array}$ & 800 metros de raio & $\begin{array}{l}500 \text { e } 1.000 \text { metros } \\
\text { de raio }\end{array}$ \\
\hline \multicolumn{2}{|c|}{$\begin{array}{c}\text { Dimensões } \\
\text { complementares }\end{array}$} & Densidade e & Densidade e & Densidade e & Densidade e \\
\hline \multicolumn{2}{|c|}{ Modo de transporte } & $\begin{array}{l}\text { Diversidade } \\
\text { Viagens não } \\
\text { motorizadas (a pé e } \\
\text { bicicleta) }\end{array}$ & $\begin{array}{l}\text { Diversidade } \\
\text { Viagens não } \\
\text { motorizadas }\end{array}$ & $\begin{array}{l}\text { Diversidade } \\
\text { Viagens a pé }\end{array}$ & $\begin{array}{l}\text { Diversidade } \\
\text { Viagens a pé não } \\
\text { recreativas }\end{array}$ \\
\hline \multirow{3}{*}{$\begin{array}{l}\text { Desenho } \\
\text { urbano }\end{array}$} & Nós & $\begin{array}{l}\text { Proporção de } \\
\text { cruzamentos em } \\
\text { cruz }\end{array}$ & $\begin{array}{l}\text { Densidade de } \\
\text { interseções }\end{array}$ & $\begin{array}{l}\text { Cruzamento em } \\
\text { cruz; } \\
\text { Densidade de } \\
\text { interseções }\end{array}$ & $\begin{array}{l}\text { Proporção de } \\
\text { interseções; } \\
\text { Índice de } \\
\text { conectividade (nós } \\
\text { - interseções / ruas } \\
\text { - ligações) }\end{array}$ \\
\hline & Ligações & $\begin{array}{l}\text { Número de ruas } \\
\text { sem saída }\end{array}$ & & & $\begin{array}{l}\text { Rota direta; } \\
\text { Densidade da rua } \\
\text { (área de rua / área } \\
\text { de terra) }\end{array}$ \\
\hline & Ciclos & $\begin{array}{l}\text { Número de } \\
\text { quarteirões; } \\
\text { Padrão } \\
\text { predominante } \\
\text { (malha regular, } \\
\text { malha curvilínea) }\end{array}$ & $\begin{array}{l}\text { Tamanho médio } \\
\text { dos quarteirões }\end{array}$ & $\begin{array}{l}\text { Tamanho médio } \\
\text { dos quarteirões; } \\
\text { Densidade de } \\
\text { quarteirões }\end{array}$ & $\begin{array}{l}\text { Tamanho médio do } \\
\text { lote }\left(\mathrm{m}^{2}\right) ; \\
\% \text { dos quarteirões } \\
\text { contendo moradia e } \\
\text { controle de acesso; } \\
\text { Porcentagem de } \\
\text { lotes quadriláteros. }\end{array}$ \\
\hline
\end{tabular}

Fonte: (Rodrigues, 2013)

Observam-se em tais estudos diversas variáveis com diferentes nomenclaturas, entretanto, todas elas estão relacionadas aos nós, ligações e ciclos (Parthasarathi e Levinson, 2013). O uso desses elementos se justifica, na medida em que a influência do desenho urbano, expresso por sua rede de caminhos nas viagens a pé, se torna maior em função, não só da quantidade de nós e ligações, mas, fundamentalmente, pelas relações mais intensas entre esses elementos configuradas pela presença de ciclos. Por isso, procurou-se organizar e classificar os indicadores de acordo com cada um desses três elementos, como mostra a Tabela 2 (Rodrigues, 2013). 


\section{Tabela 2 - Relação dos indicadores tradicionais e os elementos nó, ligação e ciclo}

\begin{tabular}{|c|c|c|}
\hline Elemento & Descrição dos indicadores & Autor(es) \\
\hline Nó & $\begin{array}{l}\text { Densidade de interseção - representará os indicadores: proporção de } \\
\text { cruzamentos em cruz; densidade de interseções; proporção de interseções; índice } \\
\text { conectividade (nós - interseções / ruas - ligações). Pressupõe-se que quanto } \\
\text { maior o número de interseções }(v) \text { por área, possivelmente, haverá caminhos } \\
\text { menores e um número maior de trajetos. É recomendável descontar as ruas sem } \\
\text { saída. }\end{array}$ & $\begin{array}{c}\text { (Cervero e } \\
\text { Kockelman, } \\
1997 ; \\
\text { Cervero e } \\
\text { Duncan, 2003; } \\
\text { Krizek, 2003; } \\
\text { Cervero } \text { et al., } \\
\text { 2009) }\end{array}$ \\
\hline \multirow{2}{*}{ Ligação } & $\begin{array}{l}\text { Número de ruas sem saída - representará o indicador: número de ruas sem } \\
\text { saída, que é um nó com somente uma ligação. Para Swenson e Dock (2003) é um } \\
\text { demérito para a rede, pois reduz as opçôes de trajeto. É muito encontrado em } \\
\text { subúrbios, criando uma sensacãa de privacidade. }\end{array}$ & $\begin{array}{l}\text { (Cervero e } \\
\text { Kockelman, } \\
\text { 1997) }\end{array}$ \\
\hline & $\begin{array}{l}\text { Densidade de ruas - representará os indicadores: rota direta; densidade da rua } \\
\text { (área de rua / área de terra). Pressupõe-se que tal densidade interfere nas opções } \\
\text { de trajeto. }\end{array}$ & $\begin{array}{c}\text { (Cervero et al. } \\
\text { 2009) }\end{array}$ \\
\hline Ciclo & $\begin{array}{l}\text { Densidade de quarteirões - representará os indicadores: número de quarteirões; } \\
\text { padrão predominante (malha regular, malha curvilínea); tamanho médio dos } \\
\text { quarteirões; densidade de quarteirões; tamanho médio do lote; \% dos quarteirões } \\
\text { contendo residências e controle de acesso; \% de lotes quadriláteros. Pressupõe-se } \\
\text { que quanto maior o número de quarteirões por área, menores os quarteirões, } \\
\text { menores comprimentos a percorrer e maiores opções de trajeto das viagens a pé. }\end{array}$ & $\begin{array}{c}\text { Cervero e } \\
\text { Kockelman, } \\
\text { 1997; } \\
\text { Cervero e } \\
\text { Duncan, 2003; } \\
\text { Krizek, 2003; } \\
\text { Cervero } \text { et al., } \\
\text { 2009) }\end{array}$ \\
\hline
\end{tabular}

Fonte: Rodrigues (2013)

Neste contexto, Rodrigues (2013) relacionou os quatro indicadores tradicionais da Tabela 2 com 12 trabalhos, que se propuseram a medir a influência da configuração da rede de caminhos na propensão da caminhada, conforme apresentado na Tabela 3.

\section{Tabela 3 - Relação dos indicadores tradicionais}

\begin{tabular}{|c|c|c|c|c|c|c|c|c|c|c|c|c|c|}
\hline Id & Indicadores & 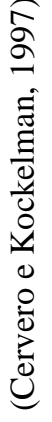 & 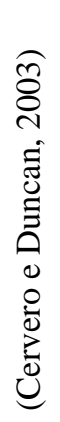 & 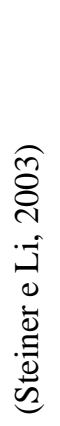 & 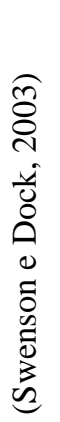 & 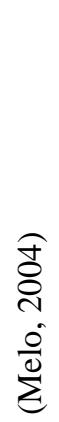 & 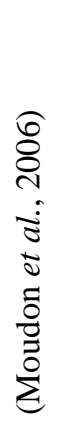 & 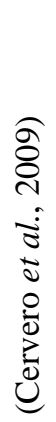 & 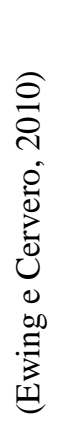 & 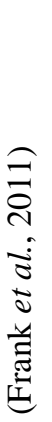 & $\begin{array}{l}\widehat{\vec{\Xi}} \\
\hat{i} \\
\hat{0} \\
\hat{0}\end{array}$ & 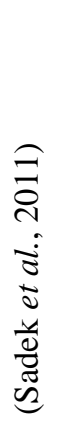 & 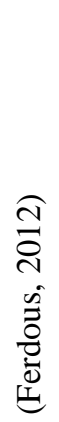 \\
\hline 1 & Densidade de interseções & $\mathrm{X}$ & $\mathrm{X}$ & $\mathrm{X}$ & $\mathrm{X}$ & & & $\mathrm{X}$ & $\mathrm{X}$ & $\mathrm{X}$ & & $\mathrm{X}$ & \\
\hline 2 & Ruas sem saída & $\mathrm{X}$ & & & $\mathrm{X}$ & & & & & & & & \\
\hline 3 & Densidade de ruas & & & & & & & $\mathrm{X}$ & & & & $\mathrm{X}$ & $\mathrm{X}$ \\
\hline 4 & Densidade de quarteirões & $\mathrm{X}$ & $\mathrm{X}$ & $\mathrm{X}$ & $\mathrm{X}$ & $\mathrm{X}$ & $\mathrm{X}$ & & & & $\mathrm{X}$ & & \\
\hline
\end{tabular}


Dentre os indicadores relacionados, dois deles se destacaram: a "Densidade de interseções" (8 em 12 consultas) e a "Densidade de quarteirões" (7 em 12 consultas). Esses indicadores são facilmente obtidos por uma simples contagem, número de interseções e quarteirões. As interseções remetem aos nós e os quarteirões ao ciclo. Este último, por levar em consideração os nós e as ligações (ruas), torna-se potencialmente mais indicado.

O segundo grupo de referências, a partir de uma extensa revisão bibliográfica de Maghelal e Capp (2011), reuniu 25 trabalhos com o intuito de desenvolver um índice voltado para o pedestre, classificados da seguinte maneira: denominação do índice, unidade espacial para análise (área ou segmento), fonte dos dados e tipo de mensuração dos dados (quantitativo ou qualitativo), bem como a preocupação em estudar o ambiente construído, levando em consideração a importância do desenho urbano (distância origem/destino, calçadas, ruas e interseções) nas viagens a pé.

Além dos 25 trabalhos mencionados, Rodrigues (2013) classificou 9 trabalhos que se propuseram a medir os índices de caminhabilidade não só no aspecto da infraestrutura (qualidade da oferta e o nível de serviço), mas na configuração da rede de caminhos, conforme mostra a Tabela 4 .

Tabela 4 - Classificação dos trabalhos sobre índice de caminhabilidade quanto aos aspectos considerados

\begin{tabular}{|c|c|c|}
\hline \multicolumn{3}{|c|}{ Aspectos } \\
\hline Qualidade da oferta & Nível de Serviço & $\begin{array}{c}\text { Configuração da rede de } \\
\text { caminhos }\end{array}$ \\
\hline $\begin{array}{l}\text { Bradshaw (1993); } \\
\text { Siebert et al. }(1998) ; \\
\text { Santos (2005); } \\
\text { Rutz et al. }(2007) ; \\
\text { Dorneles } \text { et al. }(2008) ; \\
\text { Barbosa e Moura (2010). } \\
\text { Ferreira et al. }(2010) \\
\text { Front Seat (2013); }\end{array}$ & $\begin{array}{l}\text { Bradshaw (1993); } \\
\text { Rutz et al. }(2007) ; \\
\text { Dorneles et al. }(2008) ; \\
\text { Fontenelle (2008); } \\
\text { Barbosa e Moura (2010). }\end{array}$ & Front Seat (2013); \\
\hline
\end{tabular}

Fonte: Rodrigues (2013) 
Neste contexto, Front Seat (2013) utiliza a variável distância das atividades a partir de um ponto de origem (que contempla de forma mais específica o uso misto do solo) e os indicadores tradicionais (densidade de interseções e tamanho médio dos quarteirões, ambos associados ao desenho urbano) na composição de seu índice de caminhabilidade.

Os indicadores listados por Front Seat (2013) se preocupam com a interferência da configuração da rede de caminhos na propensão da caminhada, entretanto, há equações na Teoria dos Grafos que são melhor fundamentadas matematicamente e compreendem os elementos intervenientes que expressam a conectividade (nós, ligações e ciclos), podendo produzir indicadores mais eficientes em retratar tal influência.

\section{Indicadores derivados da Teoria dos Grafos}

A Teoria dos Grafos, defendida por Raia Jr. (2000), Bocanegra (2002), Cardoso (2006), Dias (2008), Rodrigue et al. (2009) e Ferreira (2011), reúne vários indicadores que estudam a eficiência de uma rede no geral e, em particular, a rede de caminhos. Em sua definição clássica a Teoria dos Grafos é um ramo da matemática que estuda as relações entre os objetos (grafos) de um determinado conjunto (nós e ligações ou vértices e arestas) representado matematicamente, na qual o movimento de pessoas, mercadorias e informações podem ser modelados (Boaventura e Jurkiewicz, 2009; Rodrigue et al., 2009).

Neste contexto, a Teoria dos Grafos possui indicadores que se preocupam em medir a importância dos nós (Tabela 5), das ligações (Tabela 6) e dos ciclos (Tabela 7), sendo que os ciclos são os que conceitualmente melhor representam a conectividade e, consequentemente, tendem a melhor medir a influência da rede de caminhos nas viagens a pé.

Tabela 5 - Relação dos indicadores da Teoria dos Grafos, o atributo nó

\begin{tabular}{lcc}
\hline \multicolumn{1}{c}{ Descrição dos elementos } & Autor(es) & Equação \\
\hline Acessibilidade de cada nó - sintetiza as & (Raia Jr., 2000) & \\
condições de acessibilidade de cada nó em & & \\
termos de eficiência da rede, enfatizando o & & $\mathbf{N}^{\circ}$ \\
efeito da infraestrutura. $A_{i}$ é a acessibilidade & $N_{i j}$ \\
do nó $i ; N_{i j}$ é a impedância entre o nó $i$ e o & $A_{i}=\frac{E_{i j}}{\sum_{j=1}^{n} M_{j}}$ \\
centro de atividades de destino $j ; E_{i j}$ é a & \\
impedância Euclidiana entre $i$ e $j$, assumindo & & \\
infraestrutura de eficiência ótima, e $M_{j}$ é a & & \\
massa do centro econômico de destino. &
\end{tabular}




\section{Tabela 5 - Relação dos indicadores da Teoria dos Grafos, o atributo nó}

\begin{tabular}{|c|c|c|c|}
\hline Descrição dos elementos & Autor(es) & Equação & $\mathbf{N}^{\circ}$ \\
\hline $\begin{array}{l}\text { Acessibilidade por tempo e custo } \\
\text { generalizado - Considera a soma ponderada } \\
\text { do número de oportunidades de empregos } \\
\text { dentro de um tempo de viagem daquela zona, } \\
\text { sendo que os empregos incluídos são } \\
\text { determinados por categorias de rendas e } \\
\text { classes de empregos. Onde: } A I(T)_{i} \text { o índice de } \\
\text { acessibilidade para zona } i \text { usando o tempo de } \\
\text { viagem } T \text { em minutos; } j \text { é a categoria de } \\
\text { renda, variando de } 1,2, \ldots, J ; k \text { é a categoria } \\
\text { de ocupação ou classe de trabalho, variando } \\
\text { de } 1,2, \ldots, K \text {; } P_{i j k} \text {, a proporção da força de } \\
\text { trabalho da zona } i \text { e a categoria de ocupação } \\
k \text {; } E(T)_{i j k} \text { representa as oportunidades de } \\
\text { emprego (em centenas) na categoria de renda } \\
j \text { e categoria de ocupação } k \text { dentro da faixa } T \\
\text { minutos de viagem da zona } i \text {; e } 1 / 100 \text { é um } \\
\text { fator de escala. }\end{array}$ & $\begin{array}{l}\text { (Raia Jr., 2000; } \\
\text { Ferreira, 2011) }\end{array}$ & $A I(T)_{i}=\frac{1}{100} \sum_{j=1} \sum_{k=1}^{K} P_{i j k} E(T)_{i j k}$ & (2) \\
\hline $\begin{array}{l}\text { Acessibilidade de rota por região - Leva } \\
\text { em conta os parâmetros de tempo, número de } \\
\text { rotas e capacidade destas rotas. } \\
\text { Onde: } A_{i j} \text { a acessibilidade entre as regiões } i \text { e } \\
j ; c_{i j n} \text { é a capacidade média da rota } n \text { entre } i \text { e } \\
j ; n \text { o número de rotas; e } t_{i j n} \text { é o tempo médio } \\
\text { de viagem entre } i \text { e } j \text { na rota } n \text {. }\end{array}$ & $\begin{array}{l}\text { (Raia Jr., 2000; } \\
\text { Bocanegra, 2002; } \\
\text { Dias, 2008) }\end{array}$ & $A_{i j}=\frac{\sum_{n=1}^{n} c_{i j n}}{1000} \times\left(\frac{\sum_{n=1}^{n} t_{i j n}}{n}\right)$ & (3) \\
\hline $\begin{array}{l}\text { Índice de Shimbel (nodalidade) - Uma } \\
\text { medida de acessibilidade que representa a } \\
\text { soma do comprimento [distância] de todos os } \\
\text { caminhos mais curtos ligando todos os outros } \\
\text { nós no grafo. É o número de ligações } \\
\text { conectadas a ele e uma medida eficaz da } \\
\text { importância nodal. Quanto maior seu valor, } \\
\text { mais importante é o nó em um grafo e muitas } \\
\text { ligações convergem para ele. A medida } \\
\text { inversa também é chamada de distância de } \\
\text { centralidade. }\end{array}$ & $\begin{array}{l}\text { (Raia Jr., 2000; } \\
\text { Bocanegra, 2002; } \\
\text { Cardoso, 2006; } \\
\text { Dias, 2008; } \\
\text { Rodrigue } \text { et al., } \\
\text { 2009; Ferreira, } \\
\text { 2011) }\end{array}$ & $S n_{i}=\sum_{j=1}^{\infty} d_{i j}$ & (4) \\
\hline $\begin{array}{l}\text { Índice de Shimbel (global) - Uma medida } \\
\text { de acessibilidade global de uma rede }\end{array}$ & $\begin{array}{c}\text { (Raia Jr., 2000; } \\
\text { Bocanegra, 2002) }\end{array}$ & $S g_{i}=\sum_{i=1}^{n} \sum_{\substack{j=1 \\
j \neq i}}^{n} d_{i j}$ & (5) \\
\hline $\begin{array}{l}\text { Índice Theta - Razão entre a quantidade } \\
\text { média de tráfego } Q(G) \text { por interseção }(v) \text {. Um } \\
\text { teta maior, maior é a carga da rede. A medida } \\
\text { também pode ser aplicada ao número de } \\
\text { ligações }(e) \text {. }\end{array}$ & $\begin{array}{l}\text { (Rodrigue } \text { et al., } \\
\text { 2009; Levinson, } \\
\text { 2011; } \\
\text { Parthasarathi e } \\
\text { Levinson, 2013) }\end{array}$ & $\Theta=\frac{Q(G)}{v}$ & (6) \\
\hline $\begin{array}{l}\text { Densidade de interseção }- \text { Medida que } \\
\text { estima a completude da rede }\left(\mathrm{P}_{\mathrm{vb}}\right) \text {, ou seja, o } \\
\text { quanto conectado ela está. Razão entre a } \\
\text { quantidade de interseções }\left(\mathrm{V}_{\mathrm{b}}\right) \text { e a área }\left(\mathrm{A}_{\mathrm{b}}\right) \\
\text { das viagens. }\end{array}$ & $\begin{array}{l}\text { (Parthasarathi, } \\
\text { 2011) }\end{array}$ & $P_{v b}=\frac{V_{b}}{A_{b}}$ & (7) \\
\hline
\end{tabular}

Fonte: Adaptado de Rodrigues (2013) 
Esses indicadores consideram o nó como a base de suas equações. A Tabela 6 mostra as ligações, não é considerado, explicitamente, o nó na composição de suas medidas.

\section{Tabela 6 - Relação dos indicadores da Teoria dos Grafos, o atributo ligação}

\begin{tabular}{|c|c|c|c|}
\hline Descricãa dos elementos & Autor(es) & Equação & $\mathbf{N}^{\circ}$ \\
\hline $\begin{array}{l}\text { Densidade da rede }- \text { Medida da ocupação } \\
\text { territorial da rede de transporte em termos de km } \\
\text { de ligações }(L) \text { por quilômetro quadrado de } \\
\text { superfície }(S) \text {, sendo assim influenciada pela } \\
\text { extensão da rede. }\end{array}$ & $\begin{array}{c}\text { Rodrigue } \text { et al., } \\
\text { 2009; } \\
\text { Parthasarathi, } \\
\text { 2011; } \\
\text { Parthasarathi e } \\
\text { Levinson, 2013) }\end{array}$ & $N D=\frac{L}{S}$ & (8) \\
\hline $\begin{array}{l}\text { Índice PI - É a relação entre o comprimento } \\
\text { total do grafo } L(G) \text { e a distância ao longo de seu } \\
\text { diâmetro } D(d) \text {. Ele é rotulado como PI por causa } \\
\text { de sua semelhança com o valor de }(I) \text { que } \\
\text { corresponde a } 3,14 \text {, que expressa a razão entre a } \\
\text { circunferência e o diâmetro de um círculo. Um } \\
\text { alto índice mostra uma rede desenvolvida. É uma } \\
\text { medida de distância por unidades de diâmetro e } \\
\text { um indicador da forma de uma rede. }\end{array}$ & $\begin{array}{c}\text { (Rodrigue } \text { et al. } \\
\text { 2009) }\end{array}$ & $\Pi=\frac{L(G)}{D(d)}$ & (9) \\
\hline $\begin{array}{l}\text { Índice Eta - Comprimento médio por ligação. } \\
\text { Adiçãa de novos nós irá causar uma diminuição } \\
\text { de Eta( } \eta) \text { por conta do declínio do número de } \\
\text { ligações }(e) \text {. }\end{array}$ & $\begin{array}{l}\text { (Rodrigue } \text { et al., } \\
\text { 2009, Levinson, } \\
2011 ; \\
\text { Parthasarathi e } \\
\text { Levinson, 2013) }\end{array}$ & $\eta=\frac{L(G)}{e}$ & (10) \\
\hline $\begin{array}{l}\text { Circuito Médio - É a razão entre a soma das } \\
\text { distâncias }(\mathrm{km}) \text { dos pares OD }\left(\mathrm{D}_{\mathrm{nm}}\right) \text { e a soma das } \\
\text { distâncias }(\mathrm{km}) \text { euclidianas dos pares OD }\left(D_{e m}\right) \text {. }\end{array}$ & $\begin{array}{c}\text { (Parthasarathi e } \\
\text { Levinson, 2013) }\end{array}$ & $C_{t}=\frac{D_{n m}}{D_{e m}}$ & (11) \\
\hline $\begin{array}{l}\text { Porcentagem de autoestradas - É a razão entre } \\
\text { o comprimento }(\mathrm{km}) \text { de autoestradas }\left(\mathrm{L}_{\mathrm{f}}\right) \text { e o } \\
\text { comprimento da rede }\left(\mathrm{L}_{\mathrm{sm}}\right) \text { de uma região } \\
\text { multiplicado por } 100 \text {. }\end{array}$ & $\begin{array}{l}\text { (Parthasarathi e } \\
\text { Levinson, 2013) }\end{array}$ & $\% F=\frac{L_{f}}{L_{s m}}$ & (12) \\
\hline $\begin{array}{l}\text { Rede Arterial - É a razão entre o comprimento } \\
(\mathrm{km}) \text { dos segmentos de rua pertencentes a uma } \\
\text { ramificação ou rede de árvore }\left(\mathrm{L}_{\mathrm{tm}}\right) \text { e o } \\
\text { comprimento da rede }\left(\mathrm{L}_{\mathrm{sm}}\right) \text { dentro de uma área. }\end{array}$ & $\begin{array}{c}\text { (Parthasarathi e } \\
\text { Levinson, 2013) }\end{array}$ & $\emptyset_{\text {tree }}=\frac{L_{f}}{L_{s m}}$ & (13) \\
\hline
\end{tabular}

Fonte: Adaptado de Rodrigues (2013)

No entanto, outros indicadores relacionam o nó e a ligação na composição de suas medidas. Proporcionam, assim, equações que expressam outro elemento, o ciclo, cujos indicadores estão na Tabela 7. 


\section{Tabela 7 - Relação dos indicadores da teoria de grafos, o atributo ciclo}

\begin{tabular}{|c|c|c|c|}
\hline Descrição dos elementos & Autor & Equação & $\mathbf{N}^{\circ}$ \\
\hline $\begin{array}{l}\text { Número de ciclos (conexidade) - É o número } \\
\text { máximo de ciclos independentes em um grafo. } \\
\text { Este número }(u) \text { é estimado por meio do número } \\
\text { de nós }(v) \text {, ligações }(e) \text { e de subgrafos }(p) \text {. }\end{array}$ & $\begin{array}{l}\text { (Dias, 2008; } \\
\text { Rodrigue et al., } \\
\text { 2009) }\end{array}$ & $u=e-v+p$ & (14) \\
\hline $\begin{array}{l}\text { Índice Beta - Mede o nível de conectividade em } \\
\text { um grafo e é expresso pela relação entre o } \\
\text { número de ligações }(e) \text { e o número de nós }(v) \text {. } \\
\text { Árvores e redes simples têm um valor Beta } \\
\text { menor que um. A rede conectada com um ciclo } \\
\text { tem um valor de } 1 \text {. Redes mais complexas têm } \\
\text { um valor maior que } 1 \text {. Em uma rede com um } \\
\text { número fixo de nós, quanto maior o número de } \\
\text { ligações, maior o número de caminhos possíveis } \\
\text { na rede. Redes complexas têm um alto valor de } \\
\text { Beta. }\end{array}$ & $\begin{array}{c}\text { (Rodrigue } \text { et al., } \\
\text { 2009; Levinson, } \\
\text { 2011; } \\
\text { Parthasarathi e } \\
\text { Levinson, 2013) }\end{array}$ & $\beta=\frac{e}{v}$ & (15) \\
\hline $\begin{array}{l}\text { Índice Alpha - A medida de conectividade que } \\
\text { avalia o número de ciclos em um grafo em } \\
\text { comparação com o número máximo de ciclos. } \\
\text { Quanto maior o índice Alpha, maior a } \\
\text { conectividade da rede. Árvores e redes lineares } \\
\text { terão valor } 0 \text {. Um valor de } 1 \text { indica uma rede } \\
\text { completamente conectada. }\end{array}$ & $\begin{array}{l}\text { (Dias, 2008; } \\
\text { Rodrigue } \text { et al., } \\
\text { 2009; } \\
\text { Levinson, 2011; } \\
\text { Parthasarathi, } \\
\text { 2011; } \\
\text { Parthasarathi e } \\
\text { Levinson, 2013) }\end{array}$ & $\begin{array}{l}\text { (Para grafos planares) } \\
\qquad \alpha=\frac{u}{2 v-5}\end{array}$ & (16) \\
\hline $\begin{array}{l}\text { Índice Gamma - A medida de conectividade } \\
\text { que considera a relação entre o número de } \\
\text { ligações observadas e o número de ligações } \\
\text { possíveis. O valor de Gamma é entre } 0 \text { (sem } \\
\text { conexão entre os nós) e } 1 \text { (rede completamente } \\
\text { conectada, pouco usual na prática). Gamma é um } \\
\text { valor eficiente para medir a progressão de uma } \\
\text { rede no tempo. }\end{array}$ & $\begin{array}{l}\text { (Dias, 2008; } \\
\text { Rodrigue } \text { et al., } \\
\text { 2009; } \\
\text { Levinson, 2011; } \\
\text { Parthasarathi, } \\
\text { 2011; } \\
\text { Parthasarathi e } \\
\text { Levinson, 2013) }\end{array}$ & $\begin{array}{l}\text { (Para grafos planares) } \\
\qquad \gamma=\frac{e}{3(v-2)}\end{array}$ & (17) \\
\hline
\end{tabular}

Fonte: Adaptado de Rodrigues (2013)

A Teoria dos Grafos tem, portanto, uma quantidade relevante de indicadores que podem ajudar na análise e compreensão das configurações das redes de caminhos, assim como medir sua eficiência, utilizando os elementos nó, ligação e ciclo.

Todos esses indicadores trazem suas potencialidades para análise da rede de caminhos. No entanto, se faz necessário classificá-los e compará-los quanto a sua funcionalidade e simplicidade, levando em consideração os indicadores tradicionais. 


\section{Análise dos Indicadores Topológicos}

O levantamento e caracterização dos indicadores apresentados nas seções 3 e 4 serviram para mostrar as diferentes alternativas e possibilidades de mensurar o potencial da configuração da rede de caminhos em favorecer ou não a caminhada.

Algumas equações consideram o grau de importância que o nó tem sobre todos os outros nós da rede, ver Tabela 5. Outras equações levam em conta as ligações (comprimento) como o principal atributo na rede de caminhos, ver Tabela 6. Já os indicadores da Tabela 7 representam a interferência do conjunto nós, ligações e ciclos na conectividade da rede, que tende a influenciar na propensão das viagens a pé.

Na comparação dos indicadores Tradicionais com os da Teoria dos Grafos, conforme Tabela 8, alguns deles apresentam uma agilidade aparentemente maior na análise da configuração da rede de caminhos, pois se utilizam de valores absolutos e de cálculo mais direto.

\section{Tabela 8 - Relação dos indicadores tradicionais e da Teoria dos Grafos em relação aos elementos nós, ligações e ciclo}

\begin{tabular}{|c|c|c|c|}
\hline \multirow{2}{*}{ Indicadores } & \multicolumn{3}{|c|}{ Elementos da configuração da rede de caminhos } \\
\hline & Nós & Ligações & Ciclos \\
\hline \multirow[t]{2}{*}{ Tradicional } & $\begin{array}{c}\text { Densidade de } \\
\text { interseções }\end{array}$ & Densidade de Ruas. & \multirow{2}{*}{$\begin{array}{c}\text { Densidade de } \\
\text { quarteirôes }\end{array}$} \\
\hline & \multicolumn{2}{|c|}{ Ruas sem saída. } & \\
\hline \multirow[t]{2}{*}{ Teoria dos Grafos } & $\begin{array}{c}A_{i}(1) \\
A I(T)_{i}(2) ; \\
A_{i j}(3) ; \\
S n_{i}(4) ; \\
S g_{i}(5) ; \\
\theta(6) ; \\
P_{v b}(7) . \\
\end{array}$ & $\begin{array}{c}N D(8) ; \\
\Pi(9) ; \\
\eta(10) ; \\
C_{t}(11) ; \\
\% F(12) ; \\
\emptyset_{\text {tree }}(13) \text {. }\end{array}$ & \multirow[t]{2}{*}{$\begin{array}{l}u(14) ; \\
\alpha(16) ; \\
\gamma(17)\end{array}$} \\
\hline & & & \\
\hline
\end{tabular}

Fonte: Adaptado de Rodrigues (2013)

Alguns dos indicadores tradicionais também se encontram formalizados na Teoria dos Grafos. A Densidade de interseções é contemplada na Equação $7\left(P_{v b}\right)$, a Densidade de ruas pela Equação $8(N D)$ e a Densidade de quarteirões com a Equação $14(u)$. O indicador Ruas sem saída, que são os nós com uma única ligação, é utilizado na concepção dos indicadores 
Densidade de interseções e de ruas. Os indicadores tradicionais são formados por valores absolutos, enquanto os da Teoria dos Grafos, salvo as Equações 4, 5 e 14, são relativizados, ou seja, há uma razão entre suas grandezas: a existente e a desejável, o que possibilita a análise comparativa entre diferentes redes de caminhos e a classificação das mesmas. Naturalmente, em termos teóricos, tais indicadores da Teoria dos Grafos, que permitem se relativizar os resultados, se mostram com maior potencial de utilização, em particular o da Equação $16(\alpha)$, por ainda considerar os ciclos.

$\mathrm{Na}$ prática, ao aproveitar o conceito que reforça o papel dos ciclos na determinação da conectividade e, consequentemente, nas condições que favorecem a caminhada, no caso dos indicadores tradicionais, pode ser destacado o número de quarteirões em uma dada área. Tal indicador tem o mesmo significado que o número de ciclos, como citado, podendo, também, ser determinado de maneira fácil. O mesmo se aplica ao tamanho dos quarteirões que tem uma relação inversa ao seu número. Inclusive alguns autores têm estudado tais indicadores.

Krizek (2003) considera ser preferível medir a influência do desenho urbano nas viagens a pé pelo tamanho dos quarteirões do que por sua forma geométrica. Supõe, por exemplo, que um desenho urbano, com interseções espaçadas em cerca de $300 \mathrm{~m}$, é menos favorável ao deslocamento do pedestre do que para um espaçamento de $120 \mathrm{~m}$. Então, o tamanho dos quarteirões e a sua densidade é mais indicado na medição do índice de acessibilidade dos bairros, considerando que o fundamental no desenho geométrico para incentivar as viagens a pé são a distância entre as atividades, a continuidade da caminhada e as opções de trajeto.

Sobre esse tema, Chisholm (2002) registra que os quarteirões têm em média 365 m, com variação de 240 m a 490 m. Já para SFDT (2010), a média é de 150 m com os quarteirões com variação de $200 \mathrm{~m}$ a 410 m. Enquanto Parker (2007) sugere um comprimento máximo de $90 \mathrm{~m}$ para uma área com boa conectividade, o que difere um pouco dos novos urbanistas que recomendam o uso de quarteirões de $70 \mathrm{~m}$. por $90 \mathrm{~m}$. Cervero et al. (2009) acrescentam que pequenos quarteirões, por exemplo de $40 \mathrm{~m}$ por $40 \mathrm{~m}$, produzem redes altamente densas e conectadas.

O Front Seat (2013) teve uma preocupação em detalhar um pouco mais e quantificar a influência do tamanho médio dos quarteirões no seu índice de caminhabilidade, conforme 
mostra a Tabela 9, que estabelece que tal índice não é prejudicado para quarteirões inferiores a $120 \mathrm{~m}$, mas com maior penalização para quarteirões acima de $195 \mathrm{~m}$.

Tabela 9 - Tamanho médio dos quarteirões (metros)

\begin{tabular}{ll}
\hline Tamanho dos quarteirões & Penalidade $\mathbf{( \% )}$ \\
\hline Abaixo de $120 \mathrm{~m}$ & 0 \\
\hline $120-150 \mathrm{~m}$ & 1 \\
\hline $150-165 \mathrm{~m}$ & 2 \\
\hline $165-180 \mathrm{~m}$ & 3 \\
\hline $180-195 \mathrm{~m}$ & 4 \\
\hline Acima de $195 \mathrm{~m}$ & 5 \\
\hline
\end{tabular}

De acordo com a Tabela 9 e considerando os demais estudos consultados, pode-se propor, como uma escala preliminar, três faixas de tamanho de quarteirões que, simplificadamente, indicam as potencialidades da área quanto a condições que estimulam a caminhada:

- Alto potencial: inferior a 120 metros;

- Médio potencial: de 120 a 180 metros;

- Baixo potencial: superior a 180 metros.

\section{Conclusão}

A promoção das viagens a pé vem se tornando um elemento fundamental nas agendas públicas, não só para os transportes mas também para outros setores, como o da saúde e o do urbanismo. Levando em conta que o ambiente construído afeta a propensão à caminhada, foi desenvolvido o conceito de caminhabilidade, que indica as condições físicas e percebidas que expressam a qualidade de se deslocar a pé.

Neste artigo, no ambiente construído, um destaque é dado ao desenho urbano e principalmente à configuração da rede de caminhos dos pedestres e da conectividade por ela proporcionada. Considera-se que tal conectividade - ao interferir na continuidade, no comprimento e número dos itinerários alternativos entre dois pontos geradores de viagens, as realizadas a pé podem se tornar relativamente atraentes. 
As redes de caminho podem assumir diversos formatos e serem representadas por nós (interseções e travessias), ligações (ruas e calçadas) e ciclos (quarteirões). Conceitualmente, a conectividade de uma rede está relacionada à quantidade de nós, ligações e ciclos. O uso desses elementos se justifica, na medida em que a influência do desenho urbano, expresso por sua rede de caminhos, nas viagens a pé se torna maior em função não só da quantidade de nós e ligações, mas fundamentalmente pela presença de ciclos.

Distintos indicadores têm sido concebidos para medir a conectividade da configuração da rede de caminhos, pressupondo-se que ela influencia a caminhabilidade e, consequentemente, a propensão das viagens a pé. A partir de ampla revisão bibliográfica, tais indicadores foram levantados, caracterizados e organizados em dois grupos: os tradicionais e os derivados da Teoria dos Grafos, que se destacam pela sua formalização e fundamentação matemática.

A sistematização dos indicadores contribuiu para se ter uma melhor compreensão das alternativas que se dispõe para se representar a conectividade da rede de caminhos e estudar possíveis relações com a disposição das pessoas se deslocarem a pé. Os indicadores baseados no número de ciclos (Teoria dos Grafos) e, por analogia, dos quarteirões (indicadores tradicionais) tendem a ser mais completos e representativos do fenômeno investigado. Suplementarmente se acrescentam os indicadores da Teoria de Grafos, que relativizam a situação existente e a desejável, o que possibilita a análise comparativa entre diferentes redes de caminhos e a classificação das mesmas.

O artigo também contribui em termos práticos ao propor uma escala, baseada no tamanho médio dos quarteirões, que pode ser utilizada para estabelecer áreas potencialmente indicadas para a implantação de PGV orientados a viagens a pé, o que pode garantir uma demanda que viabilize o empreendimento, mas comprometido com uma mobilidade sustentável.

Por outro lado, reconhece-se que a escolha dos indicadores, com melhor capacidade para representar a configuração da rede de caminhos e explicar a relação com a propensão da caminhada, sugere a aplicação em áreas, calculando-se tais indicadores e os correlacionando com a geração de viagens a pé observadas no local. 
Reconhece-se, também, que o desenho urbano é apenas um dos vários fatores que determinam as pessoas a optarem pela caminhada em seus deslocamentos, cuja complexidade precisa ser considerada nessa modelagem. Isso reforça, também, a limitação que se observa na escala proposta de forma exploratória, que deveria incentivar novas pesquisas, a fim de melhor investigar tais relações entre o tamanho dos quarteirões e a geração de viagens numa dada localidade, considerando a multiplicidade de variáveis que interferem nesse processo e as especificidades das cidades de países em desenvolvimento, como os da América Latina.

\section{Agradecimentos}

Ao CNPq e à Rede Ibero-Americana de Estudo em Polos Geradores de Viagens (http://redpgv.coppe.ufrj.br) pelo suporte ao desenvolvimento dessa pesquisa. Também ao Fondo Nacional de Ciencia, Tecnología e Innovación de Venezuela pelo apoio oferecido à Professora Josefina Flórez.

\section{Referências}

Abley, S. e Tuner, S. (2011) Predicting walkabilitay. New Zeland Transport Agency Research Report 452.

Alcaldía Mayor de Bogotá - AMB (2011) Informe de indicadores encuesta de movilidad de Bogotá 2011. Bogotá: Autor.

Alfonso, M., Boarnet, M., Day, K., McMillan, T. e Anderson, C. L. (2008) The relationship of neighbourhood built environment features and walking. Journal of Urban Design, vol. 13, n. 1, pp. 29-51.

Amâncio, M. A. e Sanches, S. P. (2005) Identificação das variáveis do meio físico urbano que incentivam os deslocamentos pelo modo a pé. Anais do lo Congresso Luso Brasileiro para o Planejamento Urbano, Regional, Integradoe Sustentável, n. 184.

Appleyard, D. (1981) Livable streets. Berkeley: University of California Press.

Austroads (2013) Guide information for pedestrian facilities. Sydney: Autor.

Blumenfeld-Lieberthal, E. (2009). The topology of transportation networks: a comparison between different economies. Netw Spat Econ 9. pp. 427-458.

Boaventura, P. O. e Jurkiewicz, S. (2009) Grafos: introdução e prática. São Paulo: Ed. Blucher.

Bocanegra, C. W. R. (2002) Procedimento para tornar mais efetivo o uso das redes neurais artificiais em planejamento de transporte. Dissertação (Mestrado) - Escola de Engenharia de São Carlos - Universidade de São Paulo, São Carlos.

Buchanan, C. (1964) Traffic in Towns. Penguin Books.

Cardoso, C. E. P. (2006). Acessibilidade - alguns conceitos e indicadores. Revista dos Transportes Públicos - ANTP - Ano 29 - 2006 - $4^{\circ}$ trimestre.

Cervero, R. e Kockelman, K. (1997) Travel demand and 3 Ds: Density, Diversity and Design. Transportation Research Part D, vol. 2, n. 3, pp. 199-219. 
Cervero, R. e Duncan, M. (2003). Walking, bicycling, and urban landscapes: evidence from the San Francisco Bay Area. Am J Public Healthy, vol. 93. n. 9, pp. 1478- 1483.

Cervero, R., Sarmiento, O. L., Jacoby, E., Gomez, L. F. e Neiman, A. (2009) Influences of built environments on walking and cycling: lessons from Bogotá. International Journal of Sustainable Transportation, vol. 3, n. 4, pp. 203-226.

Chisholm, G. (2002) Transit-oriented development and joint development in the United States: A Literature Review. Transit Cooperative Research Program. Research Results Digest, VI Public Transit, n. 52.

Corporación Andina de Fomento - CAF (2010) Observatorio de movilidad urbana para América Latina. Bogotá: Autor. Disponível em: www.caf.com/publicaciones

Crane, R. (1999) The impacts of urban form on travel: A critical review. Report. Mass: Lincoln Institute of Land Policy.

Cuthbert, A. R. (2005) A Debate from down-under: spacial political economy and urban design. Urban Design International, n. 10, pp. 223-234.

Dias, R. F. (2008) Procedimento para elaboração do índice de acessibilidade com apoio de Sistema de Informação Geográfica - SIG. Dissertação (Mestrado em Engenharia de Transportes), COPPE, Universidade Federal do Rio de Janeiro, Rio de Janeiro. Cap. II, pp. 12-31.

Ewing, R. e Cervero, R. (2010) Travel and the built environment. Journal of the American Planning Association, vol. 76, n. 3, pp. 265-294.

Federal Highway Administration, U.S. Department of Transportation - FHWA (1999) Guidebook on methods to estimate non-motorized travel: overview of methods. FHWA-RD-98-165. Virginia: autor.

Federal Highway Administration - FHWA (2012) Report to the U.S. Congress on the outcomes of the nonmotorized transportatio piloto program SAFETEA-LU Section 1807. Autor.

Ferdous, F. (2012) The spatial analysis and morphological evolution of the 'Bazaar Streets' and urban structure of Dhaka city. Macmillan Publishers Ltd. Urban Design International, pp. 1-15. Disponível em: www.palgrave-journals.com/udi/

Ferreira, D. I. R. (2011) Indicadores de acessibilidade. Contributos para a síntese de conhecimento. Lisboa: Departamento de Prospectiva e Planejamento e Relações Internacionais.

Ferreira, M., Gramani, L. e Kaviski, E. (2010) Teoria de tráfego de pedestre usando os conceitos de fluído para um sistema macroscópico. XVI Congresso Pan-Americano de Engenharia de Tráfego e Transportes e Logística. Lisboa.

Flórez, J. (1998) Urban development patterns and their relationships with travel behaviour. Policy, Planning and Sustainability. Proceedings of Seminar B. European Transport Conference, vol. 1, pp. 315-330.

Flórez, J. (2007) Factors affecting the decision to walk: an exploratory case study in Caracas. 11th World Conference on Transport Research. Berkeley. Compendium of papers CD-Rom.

Florida Department of Transportation and Department of Community Affairs - FTOD (2011) A framework for transit oriented development in Florida. Florida: Autor. Disponível em: www.reconnectingamerica.org/assets/Uploads/201103FloridaTODFramework.pdf

Frank, L. e Engelke, P. (2001) The built environment and human activity patterns: exploring the impacts of urban form on public health. Journal of Planning Literature, vol. 16, n. 2. 
Frank, L. D., Greenwald, M. J., Kavage, S. e Devlin, A. (2011) An assessment of urban form and pedestrian and transit improvements as an integrated GHG Reduction Strategy. Washington State Department of Transportation, WA.

Frenkel, D. B. (2008) A Revitalização urbana e as viagens a pé: uma proposta de procedimento auxiliar na análise de projetos. Dissertação (Mestrado em Engenharia de Transportes), COPPE, Universidade Federal do Rio de Janeiro, Rio de Janeiro.

Gallagher, N. A., Gretebeck, K. A., Robinson, J. C., Torres, E. R., Murphy, S. L. e Martyn, K. K. (2010) Neighbourhood factors relevants for walking in order, urban, african american adults. Journal of Aging and Physical Activity, vol. 18, n. 1, pp. 99-115.

Gehl, J. e Gemzoe, L. (2003) Winning back public space. In: Tolley, R. (Ed.), Sustainable transport, planning for walking and cycling in urban environments. Cambridge: Woodhead

Georgia Department of Transport - GDOT (2003) Pedestrian and streetscape guide. EUA: Autor.

Hall, P. (1993) Cities of tomorrow. Primera edición: 1988. Oxford: Blackwell.

Hess, P. M., Moudon, A. V. e Logsdon, M. G. (2001) Measuring land use patterns for transportation research. Transportation Research Record, n. 1780, pp. 17-24.

Hirsch, J. A., Moore, K. A., Evenson, K. R., Rodriguez, D. A. e Roux, A. V. D. (2013) Walk scores and transit scores and walking in the multi-ethnic study of atherosclerosis. American Journal of Preventive Medicine, vol. 45, n. 2, pp. 158-166.

Institute of Transportation Engineers - ITE (2011) Planning urban roadway systems: an ite proposed recommended practice. Washington, DC: Autor.

Jonietz, D. e Timpf, S. (2012) Incorporating the influence of walkability into a model of pedestrian accessibility; pp. 31-43. Transportation Demand Management. TUM - Technische Universitat Munchen.

Kelly, C.E, Tight, M. R, Hodgson, F.C. e Page, M. W. (2011) A comparison of three methods for assessing the walkability of the pedestrian environment. Journal of Transport Geography, n. 19, pp. $1500-1508$.

Krizek, K. J. (2003) Operationalizing neighborhood accessibility for land use - travel behavior research and regional modeling. Journal of Planning Education and Research 22. pp. 270-287.

Levinson, D. (2011) Network structure and city size. University of Minnesota: Nexus Research Group. Working Papers. Department of Civil Engineering, 500 Pillsbury Drive SE, Minneapolis, MN. 55455 USA. Disponível em: nexus.umn.edu.

Litman, T. (2008) Creating safe and healthy communities. Environments Journal, vol. 35, n. 3, pp. 2143.

Litman, T. (2009) Well measured: developing indicators for comprehensive and sustainable transport planning, Victoria Transport Policy Institute. Disponível em: www.vtpi.org/wellmeas.pdf.

Litman, T. (2013a) Evaluating complete streets: the value of designing roads for diverse modes, users and activities. Victoria Transport Policy Institute. January, pp. 47. Disponível em: www.vtpi.org/equity.pdf

Litman, T. (2013b) The new transportation planning paradigma. ITE Journal. June. pp. 20-28.

Maghelal, P. K. e Capp, C. J. (2011) Walkability: a review of existing pedestrian indices. URISA Journal, vol. 23, n. 2, pp. 5-19.

Marko, J. e Johnson, S. (2008) Designing healthy places: land use planning and public health. Environments Journal, vol. 35, n. 3, pp. 9-19. 
Melo, B. P. (2004) Indicadores de ocupação urbana sob o ponto de vista da infraestrutura Viária. Dissertação (Mestrado em Engenharia de Transportes). Instituto Militar de Engenharia. Rio de Janeiro.

Mitra, R., Buliung, R. N. e Faulkner, G. E. J. (2010). Spatial clustering and the temporal mobility of walking school trips in the Greater Toronto Área, Canada. Health e Place, n. 16, pp. 646-655.

Moudon, A. V., Hess, P. M., Matlick, J. M., e Pergakes, N. (2002) Pedestrian location identification tools. Transportation Research Record, n. 1818, pp. 94-101.

Moudon, A. V., Lee, C., Cheadle, A. D., Garvin, C., Johnson, D., Schmid, T. L., Wethers, R. D., e Lin, L. (2006) Operational definitions of walkable neighborhood: theoretical and empirical insights. Journal of Physical Activity and Health, vol. 3, n. 1, pp. 99-117.

New Zealand Transport Agency - NZTA (2007) Pedestrian network planning and facilities design guide. Land Transport New Zealand, NZ.

New Zealand Transport Agency - NZTA (2009) Pedestrian planning and design guide. Wellington: autor.

New Zealand Transport Agency - NZTA (2013) Reallocation of road space. New Zealand: Autor.

Park, S. (2008) Defining, measuring, and evaluating path walkability, and testing its impacts on transit users' mode choice and walking distance to the station. Berkeley. Dissertation, University of California Transportation Center. UC Berkeley.

Parker, S. (2007) Brisbane transit-oriented master plan. Master of Urban Planning \& Policy Project. University of Illinois at Chicago. Chicago.

Parthasarathi, P. (2011) Network structure and travel. Dissertation (PhD) Faculty of the Graduate School of University of Minnesota.

Parthasarathi, P. e Levinson, D. (2013) Network structure and the journey to work: An intrametropolitan analysis. Transportation Research Board Annual Meeting. Washington, DC.

Portugal, L. S., Flórez, J. e Rodrigues, A.N. (2010) Rede de pesquisa em transportes: um instrumento de transformação e melhora da qualidade de vida. Revista Transportes, vol. 18, n. 1, pp. 6-16.

Portugal, L. S. (2012) Polos geradores de viagens orientados à qualidade de vida e ambiental: modelos e taxas de geração de viagens. Organizador. Rio de Janeiro: Editora Interciência.

Programa de las Naciones Unidas para los Asentamientos Humanos - ONU - Habitat (2012) Estado de las ciudades de América Latina y el Caribe 2012. Rumbo a una nueva transición urbana. Recife: Autor.

Raia Jr., A. A. (2000) Acessibilidade e mobilidade na estimativa de um índice de potencial de viagens utilizando redes neurais artificiais e sistemas de informações geográficas. Tese (Doutorado em Engenharia de Transportes) Escola de Engenharia de São Carlos, Universidade de São Paulo, São Carlos, capítulo III, pp. 29-58.

Reggiani, A., Bucci, P. e Russo, G. (2010) Accessibility and network structures in the german commuting. Networks and Spatial Economics, vol. 11, no. 4, PP. 621-641.

Rocha, A. S., Frenkel, D. B., Flórez, J. e Portugal, L. S. (2012). Viagens a pé, pp. 455-496, em Polos geradores de viagens orientados à qualidade de vida e ambiental: modelos e taxas de geração de viagens. Portugal, L. S. (Org.) Rio de Janeiro: Editora Interciência.

Rodrigue, J. P., Comtois, C e Slack, B. (2009) The geography of transport systems. Hofstra University, Department of Global Studies e Geography. 
Rodrigues, A. R. P. (2013) A mobilidade dos pedestres e a influência da configuração da rede de caminhos. Dissertação (Mestrado em Engenharia de Transportes), COPPE, Universidade Federal do Rio de Janeiro, Rio de Janeiro.

Sabatini, F., Cáceres, G. e Cerda, J. (2001) Segregación residencial en las principales ciudades chilenas: tendencias de las tres últimas décadas y posibles cursos de acción. EURE, Revista Latinoamericana de Estudios Urbanos Regionales, Dic, vol. 27, n. 82. Santiago: Pontificia Universidad Católica de Chile.

Sadek, A. W., Wang, Q., Su, P. e Tracy, A. J. (2011) Reducing vehicle miles traveled through smart land-use design. Final Report C-08-29. New York State Department Of Transportation. NY.

Saelens, B. E., Sallis, J. F. e Frank, L. D. (2003) Environmental correlates of walking and cycling: findings from the transportation, urban design, and planning literatures. Annals of Behavioral Medicines, vol. 25, n. 2, pp. 80-91.

Scovino, A. S. (2008) As viagens a pé na cidade do rio de janeiro: um estudo da mobilidade e exclusão social. Dissertação (Mestrado em Engenharia de Transportes), COPPE, Universidade Federal do Rio de Janeiro, Rio de Janeiro.

Speck, J. (2012) Walkable city: how downtown can save america, one step at a time. New York: Farrar, Straus and Giroux.

Stantec, (2010). Proposed walkability strategy for Edmonton. Stantec Consulting Ltda. Glatting Jackson Kercher Anglin, Inc. Project for Public Spaces.

State of Florida Department of Transportation - SFDT (2010) Estimating the transportation impacts of growth. Transportation Impact Handbook. Tallahassee: autor.

Steiner, R. L. e Li, I. (2003). Multimodal trade-off analysis in traffic impact studies. Final Report. The Florida Department of Transportation, Office of Systems Planning.

Swenson, C. J. e Dock, F. C. (2003) Urban design, transportation, environment and urban growth: transit-supportive urban design impacts on suburban land use and transportation planning. design center for american urban landscape. University of Minnesota. Minneapolis, MN. Disponível em: http://www.cts.umn.edu/trg/publications/pdfreport/ TRGrpt11/TRG11.pdf.

TransLink. (2010) Transit-oriented communities: A literature review on the relationship between the built environment and transit ridership. Vancouver: Autor.

Victoria Transport Policy Institute - VTPI (2013) Evaluating non-motorized transportation. benefits and cots. Victoria: Autor. Disponível em: www.vtpi.org/nmt-tdm.pdf.

Villota, J. (2001) Urbanismo, planificación y diseño. La cidad y sus disciplinas. Entorno urbano 1999 - 2001. Dissertação (Maestría en Diseño Urbano), Universidad Metropolitana, Caracas.

Vojnovic, I., Jackson-Elmoore, C., Holtrop, J. e Bruch, S. (2006) The renewed interest in urban form and public health: Promoting increased physical activity in Michigan. Cities, vol. 23, n.1, pp. 117.

Wey, W. M. e Chiu, Y. H. (2013) Assessing the walkability of pedestrian environment under the transit-oriented development. Habitat International, vol. 38, pp. 106-118.

Wheeler, S. (2004) Planning for sustainability: creating livable, equitable, and ecological communities, Introduction, 15-17. New York: Routledge. 